\title{
Life cycle assessments of aquaculture systems: a critical review of reported findings with recommendations for policy and system development
}

Bohnes, Florence Alexia; Hauschild, Michael Zwicky; Schlundt, Jørgen; Laurent, Alexis

Published in:

Reviews in Aquaculture (Print)

Link to article, DOI:

$10.1111 /$ raq. 12280

Publication date:

2019

Document Version

Peer reviewed version

Link back to DTU Orbit

Citation (APA):

Bohnes, F. A., Hauschild, M. Z., Schlundt, J., \& Laurent, A. (2019). Life cycle assessments of aquaculture systems: a critical review of reported findings with recommendations for policy and system development. Reviews in Aquaculture (Print), 11(4), 1061-1079. https://doi.org/10.1111/raq.12280

\section{General rights}

Copyright and moral rights for the publications made accessible in the public portal are retained by the authors and/or other copyright owners and it is a condition of accessing publications that users recognise and abide by the legal requirements associated with these rights.

- Users may download and print one copy of any publication from the public portal for the purpose of private study or research.

- You may not further distribute the material or use it for any profit-making activity or commercial gain

- You may freely distribute the URL identifying the publication in the public portal 


\title{
Life cycle assessments of aquaculture systems: a critical review of reported findings with recommendations for policy and system development
}

Florence Alexia Bohnes $^{\mathrm{a}}$, Michael Zwicky Hauschild ${ }^{\mathrm{a}}$, Jørgen Schlundt ${ }^{\mathrm{b}}$ and Alexis Laurent ${ }^{\mathrm{a}}$

a: Division for Quantitative Sustainability Assessment (QSA), Department of Management

Engineering, Technical University of Denmark (DTU), Kgs. Lyngby, Denmark.

${ }^{b}$ : Food Technology Centre (NAFTEC), Nanyang Technological University (NTU), Singapore.

* To whom correspondence should be addressed;

Technical University of Denmark

Bygningstorvet Building 116B, Room 104A

2800 Kgs. Lyngby, DENMARK

e-mail: flbo@dtu.dk; tel: (+45) 45254807

Running title: Review of LCAs on aquaculture

\begin{abstract}
$\underline{\text { Abstract }}$
The aquaculture sector is anticipated to be a keystone in food production systems in the coming decades. However, it is associated with potentially important environmental damages caused by its contribution to eutrophication or climate change, for example. To comprehensively quantify those impacts, life cycle assessment (LCA) studies have been conducted on several seafood farming systems for the past 15 years. But, what major findings and common trends can we draw from this pool of studies? What can we learn to provide recommendations to decision and policymakers in the aquaculture sector? To address these questions, we performed a critical review of 65 LCA studies of aquaculture systems from the open literature. We conducted quantitative analyses to explore which impacts can be identified as dominating and to compare different types of aquaculture systems. Our results evidenced that the feed production is a key driver for climate
\end{abstract}


change, acidification, cumulative energy use, and net primary production use, while the farming process is a key driver for eutrophication. We also found that different aquaculture systems and technology components may exert considerably different environmental impacts. Based on identified patterns and comparisons, we therefore provided specific recommendations to aquaculture stakeholders for future policy and system development. Overall, the analysis of existing studies demonstrates that important insights can be gained by applying LCA to aquaculture systems, and, to move towards an environmentally-sustainable aquaculture sector, we recommend its systematic use in the design of new aquaculture systems or policies, and/or in the evaluation and optimization of existing ones.

Keywords: aquaculture; aquafeed; environmental impacts; food production; life cycle assessment; sustainability. 


\section{Table of Contents}

Abstract............................................................................................................................................................. 1

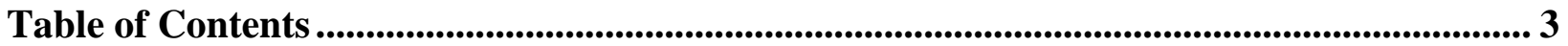

1 Introduction ................................................................................................................................. 4

2 Review Methodology ……………................................................................................................... 5

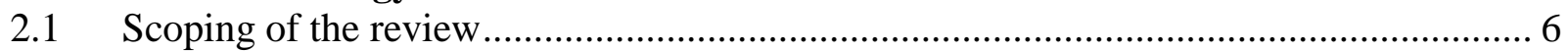

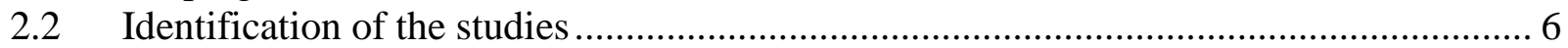

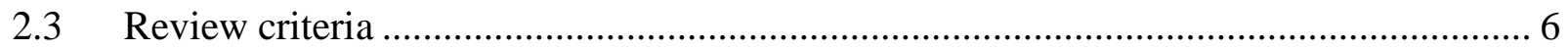

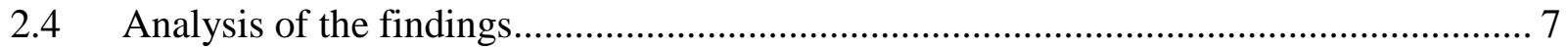

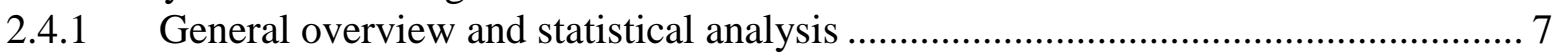

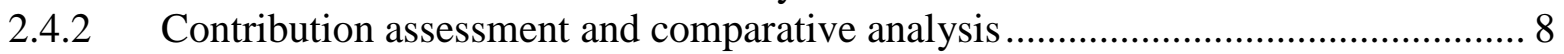

3 Overview of assessed cases and statistical analysis.............................................................. 8

3.1 Overview of LCA studies in a global perspective.......................................................... 8

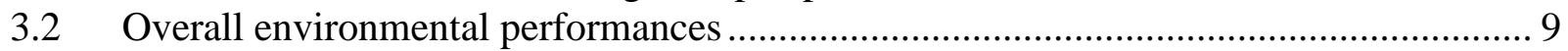

3.3 Influential system parameters.............................................................................. 11

4 Distribution of environmental impacts within aquaculture systems ................................. 12

4.1 Contribution of different system components .............................................................. 14

4.1.1 Seafood farming stage....................................................................................... 14

4.1.2 Feed production and influence of FCR .............................................................. 15

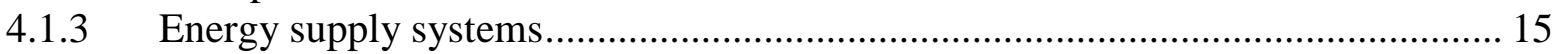

4.1.4 Importance of often-neglected components.............................................................. 16

4.2 Importance of a full life cycle perspective ………......................................................... 16

5 Comparative performances of aquaculture systems ............................................................ 17

5.1 Comparisons across aquaculture types and intensities................................................. 17

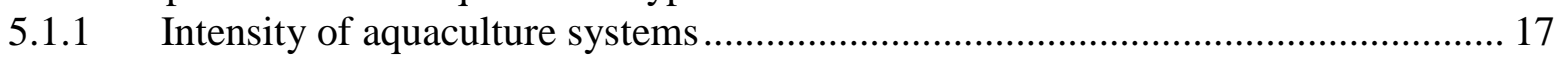

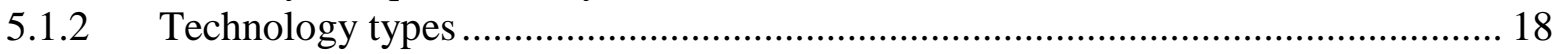

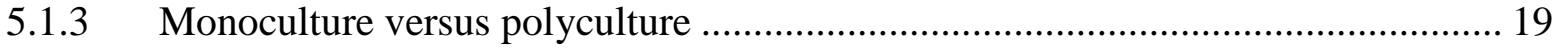

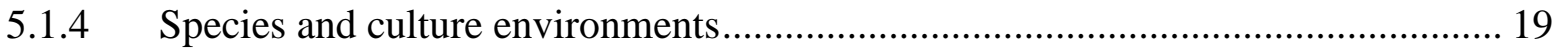

5.2 Improving feed production......................................................................................... 20

5.3 Integrated multi-trophic aquaculture: a promising approach? ....................................... 22

6 Relevance of LCA as a policy- and decision-making tool in aquaculture ........................ 23

6.1 Impact reduction potentials of aquaculture systems ……............................................. 24

6.2 What can we learn from macro scale and future-oriented studies?.................................. 24

6.3 Limitations of LCA to assess seafood production sustainability .................................. 25

7 Conclusions and recommendations......................................................................................... 26

Acknowledgements .......................................................................................................................... 27

References:.......................................................................................................................................... 28 


\section{Introduction}

Aquaculture has been identified as a promising alternative to fisheries to tackle the growing food security issue while avoiding depletion of wild fish stocks (World Bank 2013). This sector has been growing dramatically for decades, from a global production of less than 10 million tons in 1985 to 73.8 million tons in 2014 (FAO 2016). Even though seafood farming is often claimed to be sustainable (e.g. Tlusty and Thorsen 2016), it is associated with multiple potential environmental impacts such as eutrophication of aquatic ecosystems, intensive use of land and water, ecotoxicity in local ecosystems through the use of chemicals, and introduction of nonindigenous species (Naylor et al. 2000; Diana 2009; Ottinger et al. 2016). It is thus highly relevant to assess current aquaculture practices and identify the aquaculture production systems that are the most environmentally sustainable.

Environmental sustainability has been defined as the "maintenance of natural capital", also known as the input/output rules that could be summarized as followed: the waste emissions caused by a project or action should not excess the capacity of the local environment (output rule) and the natural resources should be harvested at a rate that allow regeneration (input rule) (Goodland 1995; Goodland and Daly 1996). A tool commonly used to assess the environmental sustainability of food production systems is life cycle assessment (LCA), which has already proven its value in the path to more sustainable food (Andersson 2000; Mungkung and Gheewala 2007; Ziegler et al. 2016). LCA is an ISO-standardized methodology, which quantifies the impacts on ecosystems, human health and natural resources stemming from products and systems throughout their entire life cycle, i.e. from the extraction of the raw materials through their production and use or operation up to their final decommissioning and disposal (ISO 2006; EC 2010). This tool can be used to assess multiple impact categories, such as climate change, eutrophication to aquatic environments (termed "aquatic eutrophication" hereafter), or toxicity of chemical releases impacting human health (termed "human toxicity" hereafter) and ecosystems (termed "ecotoxicity" hereafter) . LCA can be used to support decision-making in aquaculture by identifying the hotspots of a system in order to reduce their environmental impacts or by comparing several alternative systems to determine which one has the lowest environmental impacts among analyzed alternatives. This can be done at micro-level (e.g. focus on a specific process, such as feed production), meso-level (like assessing an entire farm) or macro-level (like assessing the aquaculture sector or an entire country).

Several LCA studies have been performed on aquaculture systems, as illustrated in Figure 1. Altogether, they form a considerable set of assessments, which should be comprehensively investigated to identify trends and common patterns in their findings as well as evaluate how they adapt and apply LCA to aquaculture systems and products (Ziegler et al., 2016). Although relevant, such analyses have not been reported in the literature since 2013. Most existing reviews of the application of LCAs to aquaculture systems have had a narrow scoping, e.g. focusing on a specific impact category or country (Nijdam et al. 2012; Pahri et al. 2015; Soliman and Yacout 2015; Cashion et al. 2016) or, when of a broader scope, have only considered a limited number of LCA 
studies, and/or only studies published until 2013 (Henriksson et al. 2012; Parker 2012; Aubin 2013; Cao et al. 2013; Clark and Tilman 2017). A large pool of studies - and associated findings - could therefore not be included in these reviews (see Figure 1).

The current study aims to bridge this knowledge gap by performing a comprehensive critical review of the findings and lessons learned from LCA studies of aquaculture systems, as currently available in the literature. The objectives of the study are to: (i) provide a comprehensive mapping of all the LCA studies published up to mid-2017 that included aquaculture systems producing food and aquaculture feed; (ii) conduct a statistical analysis of the LCA results to identify impact patterns and characterize environmental impacts for aquaculture systems; (iii) explore the influences and contributions of the different components of the life cycle of aquaculture systems; (iv) perform comparative analyses of the aquaculture systems, accounting for differences in intensity, technology, feed conversion ratio (FCR), and types of farmed species; and (v) discuss the relevance of LCA in a policy- and decision-making context within the field of aquaculture.

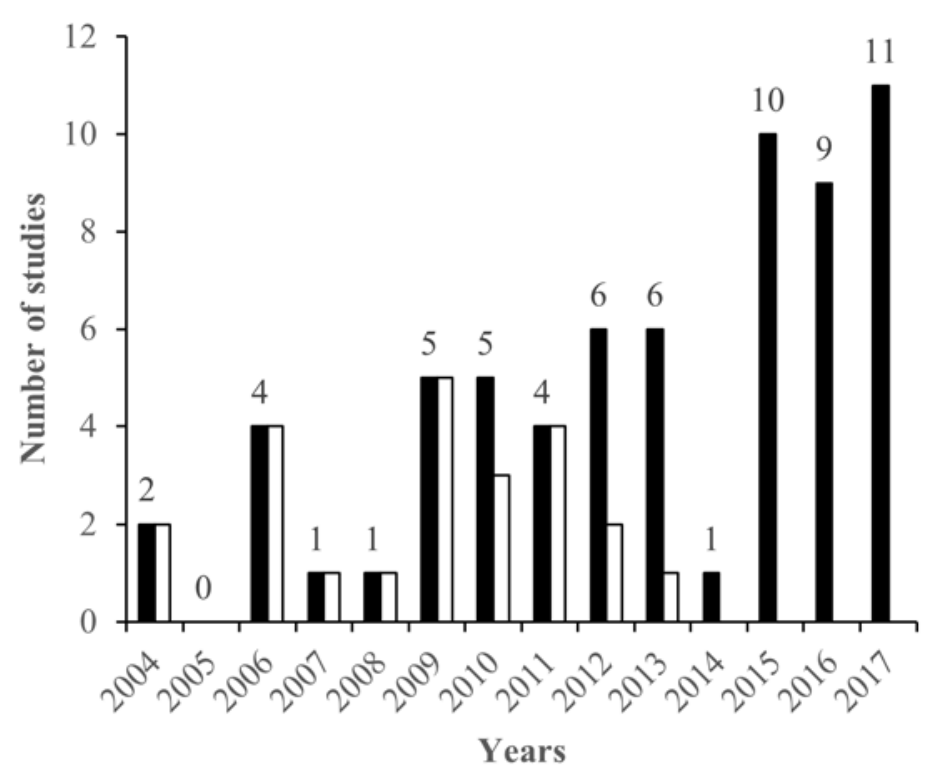

- All studies found and considered in current study (total of 65 studies)

$\square$ Studies reviewed in previously-published general critical reviews (total of 23 studies)

Figure 1: Temporal evolution in the total number of LCA studies of aquaculture systems and the ones included in general reviews published until mid-2017. 


\section{Review Methodology}

\subsection{Scoping of the review}

We included all LCA studies of one or several aquaculture systems or aquafeed production systems. Studies limited to reporting of emission inventories, social-LCA studies and pure economic assessments were dismissed. The focus being on food production, aquaculture systems designed to produce biogas, biofuels or bioactive compounds were also excluded. Fisheries, despite mainly producing food for human consumption, constitute an area of research in their own right and present other environmental problematics than aquaculture (see recent review by Ziegler et al. 2016); they were thus excluded from the scope of the study. However, studies conducting comparisons between fisheries and fish farms were included, although only the results concerning the fish farming systems were encompassed in the review. Finally, only studies including assessments of at least two environmental impact categories were included. An exception was made for Cashion et al. (2016), who considered only net primary production use (NPPU), an impact category used specifically in food production. Environmental impact categories of relevance for aquaculture systems could be climate change, aquatic eutrophication, acidification, freshwater ecotoxicity or marine ecotoxicity (Mungkung et al. 2006; Henriksson et al. 2012). Assessments of climate change or carbon footprints alone were therefore excluded. Identification of the studies

We only included studies published in scientific journals, conference proceedings and independent research center reports that were peer-reviewed and written in English. The identification of the studies was done using Web of Science database (http://webofknowledge.com) and Google Scholar search engine (https://scholar.google.dk/) with the search words "Life cycle assessment" + "aquaculture", "Life cycle analysis" + "aquaculture", "LCA" + "aquaculture", "Life cycle assessment" + "aquafeed" and "Life cycle assessment" + "aquaculture" + "feed". Additionally, the cited and citing articles in the five previously-published general critical reviews (Henriksson et al. 2012; Parker 2012; Aubin 2013; Cao et al. 2013; Clark and Tilman 2017) were crosschecked for additional studies.

\subsection{Review criteria}

The retrieved studies were analyzed and the cases they assessed were extracted. A case was defined as a system with a specific set of characteristics that has been subject to an LCA and thus assessed with regard to its contribution to some environmental impacts. For each case, the methodological characteristics of the assessment (such as the specified functional output as defined by the functional unit, or the applied life cycle impact assessment methodology), the general characteristics of the studied aquaculture system (e.g. type of culture, cultured species or geographic location), and the lessons learned from the study were extracted and categorized. The current review focuses on the two latter aspects, since an analysis of the LCA methodological aspects of the studies is the focus of another paper (Bohnes and Laurent 2018, submitted). 
Nonetheless, some central methodological aspects of importance for the analysis of the findings (like the functional unit) are also addressed here.

Similarities and differences between the cases assessed within a given study are determined from the general characteristics of the aquaculture systems. The main criteria used to map the cases are the culture intensity (intensive, semi-intensive or extensive), the culture diversity (monoculture or polyculture), the culture environment (freshwater culture or coastal culture; FAO 2017a), the species cultivated and the technologies used. The system size, despite being relevant for our analysis, was not considered as a criterion because of a lack of information available in the LCA studies reviewed. A summary of criteria with detailed definitions is available in Table S1. The main findings of the studies were extracted and linked to the characteristics of each case in order to highlight potential patterns and allow for themed analyses (see Section 2.4).

\subsection{Analysis of the findings}

The results were analyzed in two distinctive ways. First, a statistical analysis was conducted on the LCA results compiled from all retrieved cases, aiming to draw an extended picture of all studies when taken together. The findings and conclusions within each study were then gathered by theme and analyzed to find overall patterns and trends.

\subsubsection{General overview and statistical analysis}

The impact indicator scores for four commonly-assessed LCA impact categories, i.e. climate change, aquatic eutrophication, acidification and cumulative energy demand, and two aquaculturerelated impact categories, i.e. water dependence (water input relative to fish biomass production; Aubin et al. 2009) and net primary production use (NPPU), have been extracted from the studies for each case. This selection was motivated by the data availability of the indicators in the total pool of LCA studies.

The functional unit (FU), which quantifies the service or function that the system provides, was retrieved and used to harmonize the results and make them relatively comparable (see below). The FUs could be divided in two categories: (i) functional units defined as production of mass-based "live-weight product” (e.g. "1 kg of live-weight fish at farm gate"), or (ii) functional units defined as supply of mass-based "edible product" (e.g. "1 kg of fish fillet" or " $1 \mathrm{~kg}$ of edible mussels"). The usable fractions (i.e. the edible part of the seafood) used in the latter studies were retrieved to bring all results to a common basis of "live-weight FU". We chose to harmonize the cases based on the live-weight product quantity because of the large amount of studies using this type of functional unit (78\%). The relevance of such a functional unit is discussed in a follow-up paper, focusing on methodological aspects (Bohnes and Laurent 2018, submitted). It is worth noting that no further harmonization of the results was performed (e.g. consideration and/or alignment of system boundaries or LCI modelling framework), and the remaining differences must therefore be regarded as a source of uncertainties. 
The harmonized results were subject to multiple regression analyses to explore the influence of seven system characteristics: culture intensity, culture diversity, culture environment, specie(s) cultivated, technologies used, location of the system (i.e. continent) and feed conversion ratio (FCR). The analysis was done using the software R v3.4 (R Core Team 2013) and the statistical significance was assessed using F-tests once the variable tested was checked to be normally distributed.

\subsubsection{Contribution assessment and comparative analysis}

A semi-quantitative analysis was additionally conducted to identify and highlight potential trends in the main conclusions across the analyzed studies. The degree of consensus around the main findings was calculated as the ratio between the number of studies explicitly concluding on a finding and the total number of studies that were eligible to that conclusion. For example, cases assessing aquaculture systems producing non-fed species such as mussels are not eligible to conclusions regarding feed production or FCR since they do not use aquafeed. Furthermore, to compare the performances of different aquaculture system options, differences in impact scores between cases within one study were averaged and compared. Such an approach enables a more meaningful comparison between aquaculture systems because it avoids some of the methodological differences and discrepancies that may be present between different studies.

\section{Overview of assessed cases and statistical analysis}

\subsection{Overview of LCA studies in a global perspective}

In the literature collection, a total of 65 peer-reviewed studies were retrieved, containing a total of 217 cases, among which 179 were aquaculture systems (see Table S2) and 38 were aquafeed systems (see Table S3).

The overview of the studies reveals an important discrepancy between the geographical distribution of the systems assessed in the LCA studies and the global distribution of the production of farmed fish - see Figure 2A. While Asia represents approximately $90 \%$ of the global aquaculture production, only $24 \%$ of the LCA studies assessed an aquaculture system located on this continent. On the other hand, Europe is greatly over-represented among the LCA studies, with approximately half of them, while it only accounts for $3 \%$ of the global production. This suggests that concerns about environmental sustainability and the use of LCA to assess it is limited in Asia, and it therefore calls for more LCA studies performed on aquaculture systems in this region.

A similar discrepancy can be observed for the type of species covered in the studies (Figure 2B). Diadromous fishes thus only represent $7 \%$ of the global aquaculture production while they are the focus of $42 \%$ of the studies. In contrast, freshwater fishes, which represent almost $60 \%$ of the production, only account for a quarter of the studies. One explanation may be that salmon, a diadromous fish, is currently the most consumed fish from aquaculture in Europe (EUMOFA 
2015), where most LCA studies have been performed until now, which is likely why it has been investigated in many LCA studies - see Figure 2A (EUMOFA 2015).

\section{LITERATURE}

A. Continents
凹 Africa
目 Asia
$\square$ Europe
$\square$ America
$\square$ Oceania

\section{B. Species}

m Marine fishes

目Freshwater fishes

a Diadromous fishes

$\square$ Crustaceans

Molluscs
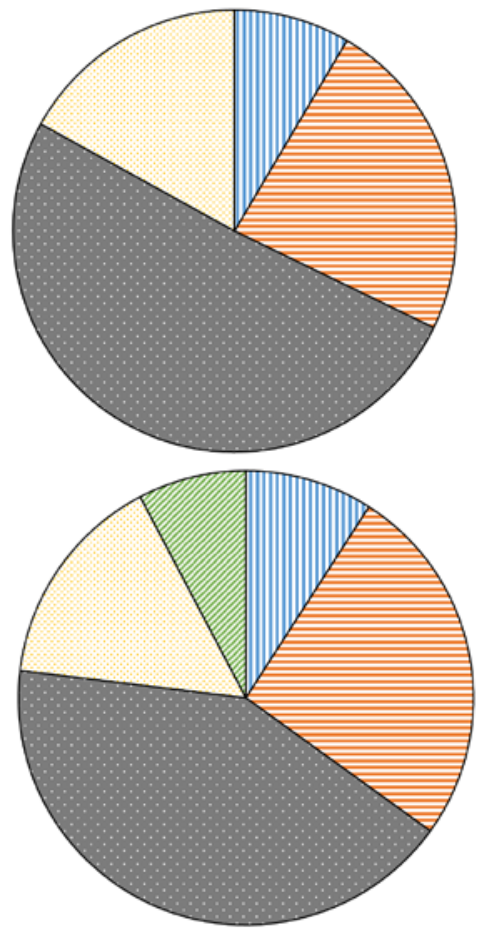

GLOBAL PRODUCTION
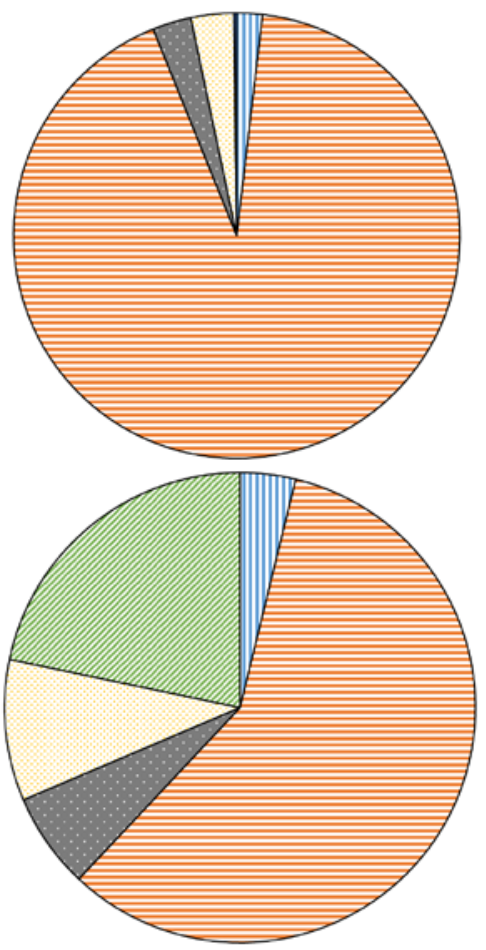

Figure 2: Differences in (A) geographical and (B) species distributions between LCA studies and actual production of farmed seafood worldwide in 2015 (data from global production extracted from FAO 2017b)

\subsection{Overall environmental performances}

Figure 3 presents the impact scores harmonized to 1 ton of live-weight seafood output for 6 selected environmental impact categories. While the range between the first and the third quartile is limited for some impact categories, like 2072-4658 kgCO2-eq/t-live-weight for climate change and 32-74 kgPO43--eq/t-live-weight for aquatic eutrophication, large variations are witnessed between the cases with the lowest and the highest scores, spanning over several orders of magnitude regardless of the considered impact category. Such discrepancies are likely to stem from different methodological choices in the scoping of the assessments. This misalignment across the scope of the studies has been recognized to significantly hamper the comparability of the studies (Brandão et al. 2012). Very scarce have been the attempts at performing comprehensive meta-analyses of LCA studies, where some of the key assumptions and methodological choices have been re-worked and harmonized, like for electricity generation technologies in 2012 (see 
Special Issue S1 in Volume 16 of J. Ind. Ecolo.; Brandão et al. 2012; Heath and Mann 2012; Lifset 2012). With respect to aquaculture systems, the generally incomplete documentation of key assumptions and methods in LCA studies precluded the possibility for such a comprehensive metaanalysis. Nevertheless, with the alignment of the functional units to bring all impact scores on a common scale (see Section 2.4.1), the obtained results are believed to give useful, albeit crude, indications of the range of impact indicator scores for aquaculture impacts.

Across the studies, an average of 4.4 tons $\mathrm{CO} 2$-eq per ton of seafood produced is found for climate change. Given that the average global consumption of fish per year is approximately $20 \mathrm{~kg}$ per capita and that half of it is farmed fish (FAO 2016), it corresponds to an impact of $44 \mathrm{~kg}$ CO2-eq per year per capita for farmed fish consumption alone, or approximately $0.6 \%$ of the annual climate change impacts of an average person in the world (Laurent et al. 2011). Similar calculations result in fish consumption taking up to $3.8 \%$ and $1 \%$ of the annual per-capita impacts for aquatic eutrophication and acidification, respectively (Sleeswijk et al. 2008). When compared to the background environmental loads from society, the contribution from aquaculture systems to aquatic eutrophication is thus higher than contributions to climate change and acidification.

Some cases were found to have negative impact scores. Negative scores may arise in cases where the multi-functionality of some processes (such as production of multiple species in the same pond) is handled by "system expansion", where the not required function is substituting an alternative way of providing it, and the aquaculture system is credited with the impact thus avoided, which may result in a negative overall sum of impacts (EC 2010). 

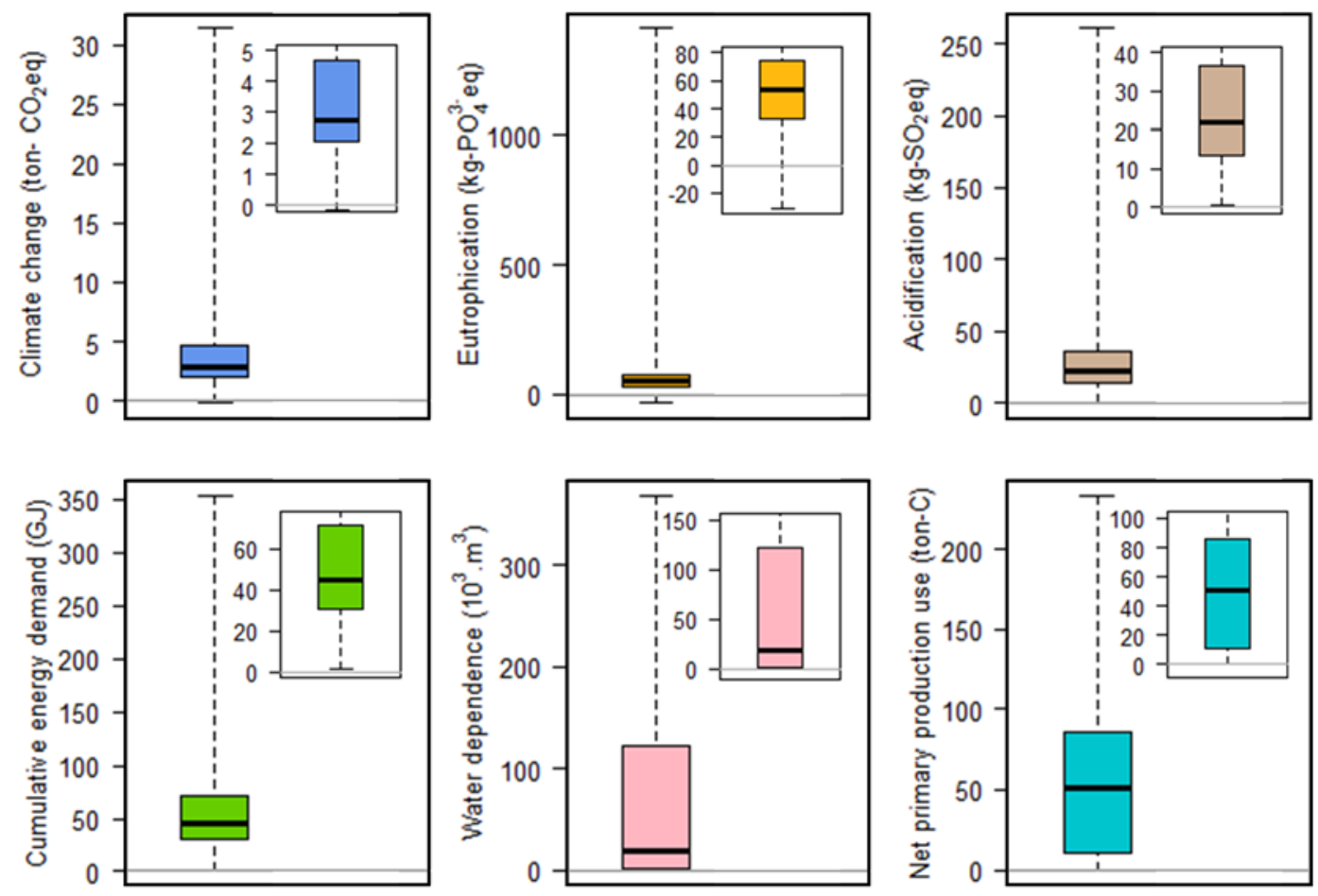

Figure 1: Impact per ton of live-weight seafood product for 6 selected impact categories (from 140 cases out of 179 , communicating usable fraction and quantitative impact results). Midline is the median; box plots indicate the first and third quartile; whiskers indicate the maximum and the minimum values retrieved.

\subsection{Influential system parameters}

To assess which factors have an influence on the results, a multiple linear regression was applied to the results of Figure 3 (excluding the country and sector level assessments), with evaluation of several parameters -see Table 1. Although uncertainties exist in the results due to, among others, different methodological choices in the studies (see Section 2.4), a number of general patterns can be identified, with very different influences exerted by the tested parameters. The farming technology thus appears to be influential for all considered impact categories but acidification, and the FCR seems influential for climate change, aquatic eutrophication and cumulative energy demand. They show that encouraging the development of some technologies over others could improve the global environmental impacts of aquaculture (see further details on this topic in Section 5.1.2). The importance of FCR, and hence of aquafeed in general, has already been highlighted by numerous LCA practitioners, and Aubin (2013) already concluded from his literature review that the feed production was the major environmental impact source. Aquafeed of carnivorous fishes in intensive systems (such as Atlantic salmon) is mainly composed of products from fisheries (FAO 2018), therefore improvement of fishing techniques will also help 
reduce the aquaculture impacts caused by the feed consumption. The importance of feed and how to improve its environmental impacts is further developed in Sections 4.1.2 and 5.2.

In contrast to species type and FCR, the culture type shows little influence on the impacts (only influential on aquatic eutrophication results). This suggests that monoculture and polyculture systems may not have significantly different impacts. This may be explained by the large variety of each system, which can use state-of-the-art technologies just as well as traditional farming methods (see section 5.1.3). With regard to the culture intensity, influence on the results was found only for acidification (see Table 1), hence environmental preference to either type of aquaculture systems can hardly be given. This may be explained by the high productivity of intensive systems that manage to balance the higher input of energy and resources. It might also be caused by the existence of an interaction between the parameter "intensity" with other parameters included in the model, such as "technology”.

The results displayed in Table 1 can provide some potential clues for improving the environmental impacts of aquaculture systems. For example, it is observed that all impacts but NPPU and water dependence seem to increase when the FCR increase. Reduction of the FCR should thus be regarded as a priority, e.g. by changing the aquafeed diet (see further details in Section 5.2). Likewise, recirculating aquaculture systems (RAS) seem to entail an increase in climate change impact and energy demand (compared to other technologies), due to the water pumping, whereas it may bring advantages in other impact categories, such as a reduced water dependence (see further details in Section 5.1.2). These are examples of parameters, on which researchers should focus to improve the environmental impacts of seafood farming (see Section 6.1).

Table 1: Overview of the results of the multiple regression applied on 6 impact categories and considering 7 explanatory variables. Statistical significance (F-test) is reflected as follows: '***' corresponds to p-value $<0.001$, ' $* *$ ' to $\mathrm{p}$-value $<0,01$, '*' to a p-value $<0,05$, "NS “ to p-value $>$ 0.05 (not significant). Symbols '(+)' and '(-)' indicate an increasing or decreasing effect of the variable on the considered impact, respectively. RAS = Recirculating aquaculture systems; FTS = Flow-through systems; NPPU = Net primary production use.

\begin{tabular}{|c|c|c|c|c|c|c|c|}
\hline \multirow[b]{2}{*}{$\begin{array}{c}\text { Impact category } \\
\qquad \operatorname{Nmax}=89^{\dagger}\end{array}$} & \multicolumn{7}{|c|}{ Explanatory variables } \\
\hline & FCR & $\begin{array}{c}\text { Culture } \\
\text { intensity }\end{array}$ & Culture type & Technology & Species & $\begin{array}{c}\text { Culture } \\
\text { environment }\end{array}$ & Continent \\
\hline Climate change & $\begin{array}{l}* * * \\
(+)\end{array}$ & & & $\begin{array}{l}* * * \\
\text { RAS (+) } \\
\text { Cage/Nets (-) }\end{array}$ & & $\begin{array}{l}* * \\
\text { Freshwater (-) }\end{array}$ & \\
\hline $\begin{array}{l}\text { Aquatic } \\
\text { eutrophication }\end{array}$ & $\begin{array}{l}* * * \\
(+)\end{array}$ & & $\begin{array}{l}\text { * } \\
\text { Polyculture (+) }\end{array}$ & $\begin{array}{l}* * * \\
\text { FTS (+) } \\
\text { RAS }(+) \\
\end{array}$ & & $\begin{array}{l}* * * \\
\text { Freshwater (-) }\end{array}$ & $\begin{array}{l}* * * \\
\text { North } \\
\text { America (-) }\end{array}$ \\
\hline Acidification & & $\begin{array}{l}\text { *** } \\
\text { Extensive } \\
(+)\end{array}$ & & & $\begin{array}{l}* \\
\text { Diadromous (-) }\end{array}$ & & \\
\hline $\begin{array}{l}\text { Cumulative energy } \\
\text { demand }\end{array}$ & $\begin{array}{l}* \\
(+)\end{array}$ & & & $\begin{array}{l}* * * \\
\text { RAS (+) } \\
\text { Cages/Nets (-) }\end{array}$ & $\begin{array}{l}* * * \\
\text { Multiple (+) }\end{array}$ & & \\
\hline Water dependence & & & & $\begin{array}{l} \\
\text { FTS (+) } \\
\text { Cages/Nets (-) }\end{array}$ & & & \\
\hline
\end{tabular}


Bohnes F.A., Hauschild M.Z., Schlundt J. and Laurent A., 2018. Life cycle assessments of aquaculture systems: a critical review of reported findings with recommendations for policy and system development. Reviews in aquaculture, 1-19. DOI: 10.1111/raq.12280

\begin{tabular}{|l|l|l|l|l|l|l|l|}
\hline & & & & RAS (-) & & & \\
\hline NPPU & & & & $\begin{array}{l}* * \\
\text { Cages/Nets (+) }\end{array}$ & $\begin{array}{l}* * * \\
\text { Crustaceans (+) }\end{array}$ & $\begin{array}{l}* \\
\text { Freshwater (+) }\end{array}$ & $\begin{array}{l}\text { As* } \\
\text { South (-) } \\
\text { America (-) }\end{array}$ \\
\hline
\end{tabular}

${ }^{\dagger}$ : Among the 179 cases of aquaculture systems that were found in total, some did not communicate the results quantitatively, or did not communicate the usable fraction or the FCR they used. They were therefore excluded from the regression. Cases assessing the aquaculture sectors within a country were also excluded.

\section{Distribution of environmental impacts within aquaculture systems}

The life cycle of an aquaculture production system includes several stages and multiple components, which we divided into: feed production, seafood farming (including hatchery and grow-out), energy supply (electricity and fuel consumption), chemical use (including fertilizers, anti-fouling agents, antibiotics and other medical agents or chemical products), infrastructures (including buildings and equipment), packaging, distribution, consumption and end-of-life (e.g. recycling of the mussel shells or valorization of fish processing residues). Figure 4 provides an overview of those components over the life cycle of aquaculture systems.

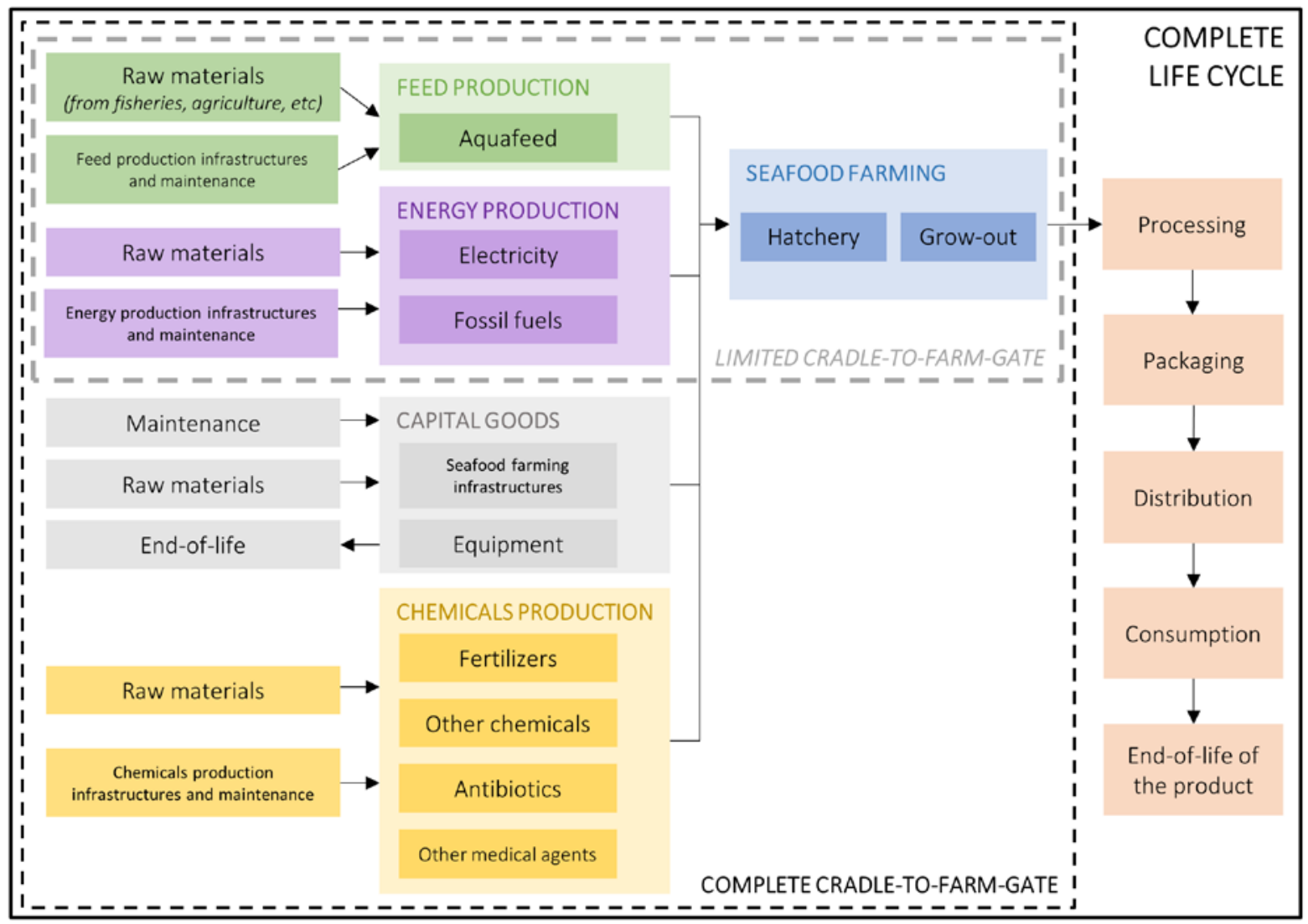


Figure 4: Life cycle of aquaculture systems broken down in its main components. Note the differences in system boundaries between limited cradle-to-farm-gate systems (grey dotted frame), complete cradle-to-farm gate systems (black dotted frame) and complete life-cycle systems (thick black line).

\subsection{Contribution of different system components}

Large environmental impacts may stem from specific stages or components within the life cycle of the aquaculture systems (like feed production, energy supply or fish production) and thus constitute environmental hotspots of the systems. Table 2 reports the degree of consensus relative to the identification of such hotspots, as explicitly stated in the retrieved LCA studies. They are further discussed in the following sub-sections.

Table 2: Summary of the qualitative meta-analysis conducted on the studies (number of studies eligible to each statement stated in brackets)

Share of studies that reports that...

...farming stage is a key driver of aquatic eutrophication (53 studies) $\quad 72 \%$

...farming stage is a key driver of water dependence (12 studies) $\quad 75 \%$

...feed production is a key driver of net primary production use (21 $\quad 86 \%$ studies)

...feed production is a key driver of acidification (48 studies) $\quad 63 \%$

...feed production is a key driver of cumulative energy demand (38 5 5 $5 \%$ studies)

...feed production is a key driver of climate change (55 studies)

$56 \%$

Share of studies that reports that...

... FCR has a major influence on the impacts (48 studies)

$56 \%$

...energy context has a major influence on the impacts (55 studies) 35\%

...infrastructures accounts for at least $5 \%$ in at least one impact category $\quad 84 \%$

(25 studies)

...chemicals/fertilizers accounts for at least 5\% in at least one impact

$78 \%$ category (18 studies) 


\subsubsection{Seafood farming stage}

In $72 \%$ of the studies, the production stage is a key driver of aquatic eutrophication impacts (Table 2) due to nitrogen and phosphorus emissions from uneaten feed and fish feces. This impact category has been identified as one of the most important when studying aquaculture production (see Section 3.2; Mungkung et al. 2006; Efole Ewoukem et al. 2012; Aubin and Fontaine 2014). Therefore, reducing the nutrient emissions from seafood farming is a key factor for developing more sustainable aquaculture production systems (Grönroos et al. 2006; Phong et al. 2011).

In $75 \%$ of the studies, the production stage is also identified as the main source of water dependence (Table 2). This impact category, specific to aquaculture production, refers to the water input relative to the fish production in mass of biota (Aubin et al. 2009). By better combining water management and nutrient input systems, an improved aquaculture production could thus be possible (Efole Ewoukem et al. 2012; Jerbi et al. 2012; Mungkung et al. 2013). However, it is important to evaluate whether such measures improve few impact categories (here aquatic eutrophication and water dependence) at the expense of others (e.g. ecotoxicity or biodiversity impact categories). This might create environmental burden shifting, which should be avoided by assessing a broad spectrum of environmental problems when performing life cycle assessment (see Bohnes and Laurent 2018, submitted).

\subsubsection{Feed production and influence of FCR}

As shown in Table 2, feed production is found to be a key driver of cumulative energy demand ( $58 \%$ of the studies), net primary production use ( $86 \%$ of the studies), acidification (63\% of the studies) and climate change (56\% of the studies). The FCR is believed to be the main cause of these results. Indeed, $56 \%$ of the studies have explicitly stated that FCR has a main influence on the environmental impacts (Table 2) and, from the statistical analysis performed in Table 1, FCR was found to be a statistically significant parameter for explaining three major impact categories.

The FCR reflects the quantity of aquafeed needed per animal weight gain during production, and is specific to a farming site. It is influenced by multiple factors, like the feed composition, the technology used, the fish species and the mortality at the site (Pelletier et al. 2009). All these factors offer possibilities for improvements that should be considered to overall decrease the FCR. Specific improvements related to decreasing impacts of feed production are further discussed in Section 5.2.

\subsubsection{Energy supply systems}

The choice of energy supply is important for the environmental performance of aquaculture systems. Over a third of the studies concluded that the energy context, including the geographical situation (determining the composition of the electricity grid mixes) had an influence on the environmental impacts -see Table 2 (among others: Aubin et al. 2009; Ayer and Tyedmers 2009; Aubin and Fontaine 2014). It is worth highlighting that this conclusion has not only been drawn about farms using recirculating aquaculture systems, but also when considering flow-through 
floating tanks (McGrath et al. 2015), traditional and cascade flow-through systems (Jerbi et al. 2012), offshore aquaculture systems (García García et al. 2016) or shellfish production farms (Lourguioui et al. 2017). Indeed, the different electricity production means present considerably different environmental impacts because the different energy sources and technologies have distinct emissions and resource uses. For example, fossil-fuel-based electricity production (such as coal or natural gas power plants) has much higher climate change impacts than electricity mixes based on hydropower, solar power or wind power, whereas the opposite tends to be observed for metal depletion (Laurent et al. 2018). Therefore, the choice of the country is crucial for new farm installations, and installing on-site renewable electricity structures should be an option to consider. Additionally, the importance of FCR has been reported to decrease when the system has more energy inputs due to a burden shifting from feed production to energy demand (Ayer and Tyedmers 2009; Samuel-Fitwi et al. 2013b), which could result in a decrease in overall impacts if the energy supply presents low environmental impacts.

\subsubsection{Importance of often-neglected components}

While all the studies considered the production stage, the feed production and the energy supply, only a few of them explicitly included the infrastructures and the chemicals used during the production (see Figure 4). In our review, 33 studies included infrastructures and 25 of them conducted a contribution analysis. Among the latter, $84 \%$ reported that infrastructures accounted for more than $5 \%$ of total life cycle impacts in at least one impact category. Contributions of up to $60 \%$ from infrastructures were even reported in the case of complex technological systems such as aquaponics (Forchino et al. 2017). Considering the important contributions that they may have in various systems and regarding different environmental impacts, infrastructures should by default be included in LCA of aquaculture systems, irrespective of the technology under study and the impact categories included.

Similarly, 35 studies included the production and use of chemicals in their assessment, and among the 18 of them that conducted a contribution analysis, $78 \%$ found out that these accounted for $5 \%$ or more in at least one impact category (see Table 2). In particular, some chlorine products used as disinfectants appeared to be toxic for humans and local organisms (Henriksson et al. 2015). However, these environmental impacts are seldom accounted for in LCA studies, as only 18 out of 55 studies encompassed some chemicals used and performed contribution analyses to evaluate their influence (studies performing LCA of aquafeed only are not considered here). Further research should therefore focus on including the production and use of chemicals, which can be comprehensively assessed in LCA studies to identify the most environmental-friendly solutions, e.g. new therapeutants or vaccines (Henriksson et al. 2017a).

\subsection{Importance of a full life cycle perspective}

To conduct a comprehensive study and avoid environmental burden-shifting from one impact category to another, all the components of a system should be included in an LCA (Hellweg and 
Milà i Canals 2014; Ziegler et al. 2016). However, most of the retrieved studies were found to only cover a cradle-to-farm-gate perspective, and therefore neglected the packaging, distribution, consumption and end-of-life of the seafood (see Figure 4). Only 16 out of 55 studies had broader system boundaries than the cradle-to-farm-gate perspective (the 10 studies performing LCA of aquafeed only are not considered here). In spite of diverging conclusions, 11 of these studies reported a strong influence on the impact results from one or more processes in these post-farm stages. Six studies additionally highlighted the importance of setting up comprehensive system boundaries and recommended to adopt a full life cycle perspective (Aubin et al. 2006; Iribarren et al. 2010b; Pahri et al. 2016; Abdou et al. 2017a,b; Fréon et al. 2017). While some post-farm stages, such as transportation, increase the environmental impacts, others, in particular in the end-of-life of the products (usually considered as by-products), can bring environmental benefits, like reuse or energy recovery processes from disposal of food waste (Iribarren et al. 2010a). Only the inclusion of a full life cycle can allow identifying such environmental trade-offs potentially arising from aquaculture systems.

\section{Comparative performances of aquaculture systems}

\subsection{Comparisons across aquaculture types and intensities}

In most of the LCA studies conducted on aquaculture systems, the aim was to compare different intensities, technologies, and/or culture types in order to identify the most environmentallyfriendly ways of producing seafood (see Table S2). The findings of these studies are analyzed in the following subsections.

\subsubsection{Intensity of aquaculture systems}

Out of the 179 retrieved cases, 53\% of them performed an assessment of an intensive system, 22\% of a semi-intensive system and $14 \%$ of an extensive system (the remaining fraction being generic systems averaging more than one intensity type). Yet, this conventional way to categorize aquaculture production hides important differences among systems. Indeed, the group "intensive systems" for instance gathers at the same time poorly-managed production farms with excessive density of fishes, and highly-optimized, state-of-the-art technologies with good management of resources and fishes. Therefore, it is not surprising that among the studies that have focused on comparing cases with different intensities, the findings differ considerably. While some studies did not find clear correlations between the intensity of the systems and the level of environmental impacts (Samuel-Fitwi et al. 2013b; Henriksson et al. 2015b), others reported that intensification of production caused an increase in emissions per functional unit (Cao et al. 2011; Efole Ewoukem et al. 2012; Samuel-Fitwi et al. 2013c; Yacout et al. 2016).

Analyzing the pool of studies retrieved in the current review, intensive systems seem to have higher impacts than low-intensity systems in global impact categories (e.g. climate change) whereas they seem to perform equally or even better with respect to more local and regional impacts (e.g. aquatic eutrophication and water use) - see Figure S1. This observation is in line with several studies, 
which evidenced that the intensification of the production leads to an environmental burden shifting from local to regional and global impacts (Aubin et al. 2006; Ayer and Tyedmers 2009; Pelletier and Tyedmers 2010; Samuel-Fitwi et al. 2013c; Dekamin et al. 2015). Indeed, more intensive systems typically require more energy for pumping water and, if the energy system relies on fossil fuels (like electricity production from coal), this translates into higher climate change and acidification impacts (global and regional). Filtering of water limits aquatic eutrophication impacts and freshwater use to levels similar to those observed for less intensive aquaculture systems. However, the intensive systems assessed and compared in this sample of studies were not stateof-the-art intensive technologies. The latter would increase productivity while lowering impacts per functional unit thanks to their better optimization of the resources, such as freshwater, and their reduced interactions with the local ecosystems (Wilfart et al. 2013; Boxman et al. 2016).

\subsubsection{Technology types}

Escapes of farmed fish is an important issue in aquaculture because of the increasing risk of spreading pathogens and the potential disturbance of the natural balance caused in the area of escape, such as introduction of new predators, invasive species or genomic differences (Naylor et al. 2000). To reduce the interactions between farmed and wild fish, aquaculture technological advancements currently focus on developing closed-systems with technologies such as recirculating aquaculture systems (RAS) (Ayer and Tyedmers 2009; Pelletier and Tyedmers 2010; Henriksson et al. 2015b). In addition to lowering the risk of escapes, closed aquaculture systems offer better opportunities to reduce the nutrient emissions in the local environment, and thus reduce the aquatic eutrophication impacts, because of their higher control of water effluents (Martins et al. 2010). This conclusion differs with the results presented in Table 1, which suggest that RAS increases eutrophication impacts compared to other technologies. This is explained by the difference in perspective between our statistical analysis, where studies are assessed altogether as a pool, and the current section which addresses studies' results individually, hence reducing uncertainties across the studies and drawing more reliable conclusions. Finally, they have better pathogen control due to the sterilization of incoming water, which reduces the mortality and thus increase the productivity of the farm (Klinger and Naylor 2012). It should be noted that extreme mortality events are not taken into account into the studies; only the average production mortality, for instance due to stress or water quality deterioration, is considered.

However, these technologies usually have a higher energy demand (Ayer and Tyedmers 2009), and studies that compare RAS with other technologies have concluded that RAS do not bring environmental benefits for all environmental impact categories, typically not for cumulative energy demand and climate change (Aubin et al. 2006, 2009; Ayer and Tyedmers 2009; SamuelFitwi et al. 2013b; Avadí et al. 2015). Such findings can also be observed when extracting the impact results from the studies included in the current review, as illustrated in Figure S2. RAS are thus found to generally have higher impacts than other systems with the exception of aquatic 
eutrophication and water dependence impacts, where they have lower impacts, and NPPU, where they have similar impacts.

Albeit being popular, RAS are not the only existing closed-system technology. Floating bags thus have been reported to show environmental benefits because of their efficient control of nutrient emissions (closed-system) while keeping a low energy demand (Ayer and Tyedmers 2009). In contrast, other technologies, such as cage farming, have been demonstrated to result in larger nutrient emissions than pond farming, where water management is easier (Henriksson et al. 2017b).

In parallel to developing new technologies, some solutions have been studied to reduce impacts of existing ones, such as a RAS based on a new Danish concept with a low energy consumption (d'Orbcastel et al. 2009) or the use of more environmentally-sustainable materials like copperalloys instead of nylon for net-pens thanks to the absence of antifouling coatings (Ayer et al. 2016).

\subsubsection{Monoculture versus polyculture}

Out of the 179 cases, $79 \%$ exclusively assessed monoculture, 12\% polyculture, and 9\% were generic studies including both (such as country scale studies). Conclusions typically vary between studies that compare monoculture and polyculture systems. Some studies could not conclude on superiority of either, typically showing better environmental performances for monoculture systems in several impact categories because of their high productivity, but also a larger energy intensity (Baruthio et al. 2008; Aubin et al. 2015). In contrast, other studies showed polyculture systems to have lower environmental impacts thanks to their potential for species complementarity (Kluts et al. 2012; Mungkung et al. 2013; Medeiros et al. 2017). To maximize the benefits, the set of species grown together needs to be chosen with different feeding habits so that they can benefit from each other's by-products and re-use nutrients across taxa (Auburn University 2017). For example, nutrient emissions could be reduced by producing fishes along with mollusks and algae, which will capture and use some of the released nutrients. This latter setting also belongs to integrated multi-trophic aquaculture systems, which are further discussed in Section 5.3.

\subsubsection{Species and culture environments}

As discussed in Section 3, the choice of the species has a statistically significant influence on the results for climate change, aquatic eutrophication, acidification, cumulative energy demand and NPPU (Table 1). It means that, on a mass unit basis, some kinds of seafood have lower environmental impacts than others. In their country-scale studies, Seves et al. (2016) thus showed that salmon is the fish species with the lowest environmental impacts among farmed fish consumed in the Netherlands, and Henriksson et al. (2017b) concluded on the superiority of catfish over carps and tilapia for the Indonesian consumption. On the other hand, Pelletier et al. (2009) found out that in salmon production, environmental performance followed a similar pattern between regions even though the production techniques differed. These results therefore suggest that some impact specificities are linked to species, as statistically demonstrated in Table 1 . However, although the 
species might have specific influence on impacts, other parameters may alter the impact results too, such as the different needs of the species in the specific situation of the study potentially varying between countries or technologies.

\subsection{Improving feed production}

As stated in Section 4.1.2, feed production was found to be a key contributor to the environmental impacts of aquaculture systems in a majority of the reviewed LCA studies (see Table 2). As a consequence, solutions to reduce the impacts associated with feed production have been explored, like new feed formulations (Ayer and Tyedmers 2009; Pelletier and Tyedmers 2010; Iribarren et al. 2012b; Santos et al. 2015; García García et al. 2016; Yacout et al. 2016; Abdou et al. 2017a; Henriksson et al. 2017b). The results of different diets are compared in Figure 5, with all the cases of aquafeed available in Table S3.

The impacts of conventional aquafeed mainly stem from the production of the raw materials, and especially the fish meal and fish oil (FMFO) ingredients because of intensive fuel use of fisheries vessels (Iribarren et al. 2012b) or low efficiency of processing plants (Fréon et al. 2017). Additionally, the aquafeed industry strives to move towards less dependence on marine resources, because of their scarcity and their higher price (Papatryphon et al. 2004). Therefore, recent studies have been focusing on replacing those ingredients by substitutes. Crop-based proteins have thus been assessed as a potential surrogate, with 7 out of 10 studies concluding that the substitution significantly improved the results (Grönroos et al. 2006; Pelletier and Tyedmers 2007, 2010; Samuel-Fitwi et al. 2013a; Avadí et al. 2015; Nhu et al. 2016; Smárason et al. 2017) while the remaining three reported that environmental impacts were comparable (Papatryphon et al. 2004; Boissy et al. 2011; Iribarren et al. 2012b). Indeed, while climate change and cumulative energy consumption usually decrease, some other impact categories might increase because of other factors (e.g. acidification due to NH3 emissions during agriculture). However, it should be noted that not all crop-based ingredients performed equally with respect to environmental impacts and therefore not all turn out to be better than FMFO ingredients (Nhu et al. 2016). An important risk is to generate environmental burden-shifting, for example with an increase of the land use and aquatic eutrophication impacts (see Figure 5). In comparison to FMFO, crop-based ingredients require agricultural processes, which are associated with larger impacts on land use (to grow products) and aquatic eutrophication potential (via use of fertilizers) (Boissy et al. 2011). Although not assessed in any of the retrieved studies, crop-based ingredients might also have higher toxic impacts than marine-based ingredients because of the use of pesticides. This calls for comprehensive studies to assess the environmental trade-offs between crop-based and marinebased ingredients with coverage of a large spectrum of environmental impacts to avoid burdenshifting (see also Bohnes and Laurent 2018, submitted).

Other substitutes to FMFO are also possible and have been assessed in previous studies, including seafood by-products (Papatryphon et al. 2004; Pelletier and Tyedmers 2007), food waste from 
human communities (like fishery vessels in Strazza et al. 2015), fly-larvae-based feed (Smárason et al. 2017) or seaweed-based feed (Seghetta et al. 2017) - see Figure 5 for comparative results. Using seafood by-products to replace FMFO shows lower environmental impacts in climate change, energy use and NPPU (Papatryphon et al. 2004), but only when the by-products originate from fisheries with low fuel consumption (Pelletier and Tyedmers 2007). Food waste from human consumption is found to have lower environmental impacts in all climate change, non-renewable energy consumption and water depletion (Strazza et al. 2015; see Figure 5). Black-fly-larvae-based aquafeed also seems promising to reduce impacts compared to FMFO, including climate change and acidification impacts, as well as human toxicity, marine aquatic ecotoxicity and abiotic depletion (Smárason et al. 2017). A major drawback about the use of fly-larvae was identified to be the higher energy demand than for FMFO, although this tendency may be explained by the immaturity of this emerging feed production pathway and could be expected to be addressed in future developments (Smárason et al. 2017).

In parallel to finding new substitutes to FMFO, another explored solution to decrease feed impacts has been to reduce the impacts of FMFO itself. For example, studies have suggested exploiting marine feed sources from lower trophic levels (Ellingsen and Aanondsen 2006; McGrath et al. 2015), or improving the quality of the production of FMFO by having cleaner, newer technology factories to produce more in each factory (because of their current drastic overcapacity in some countries - Fréon et al. 2017). Only the latter alternative has been thoroughly studied in terms of environmental impact coverage, and results showed an improvement in all impact categories included in the ReCiPe 2008 methodology (Goedkoop et al. 2013) with for example reductions of $50 \%$ in climate change and aquatic eutrophication impacts, $80 \%$ in water use and $60 \%$ in fossil depletion.

Regardless of above and because of the found importance of FCR (see Section 4.1.2), a better substitute is a substitute which would also increase feed efficiency, because it would decrease the mass of feed needed per mass of fish produced which in turn would also decrease nutrient load during the aquaculture production phase since these primarily stem from release of uneaten feed and feces (Grönroos et al. 2006). Such aspects have not been well included in previous studies. Therefore, there is a need for more LCA studies about aquafeed that involve fish nutrition experts, and thus avoid the risk of problem-shifting if the new diet results in a higher FCR (Pelletier and Tyedmers 2010; Avadí et al. 2015; McGrath et al. 2015; Smárason et al. 2017). 


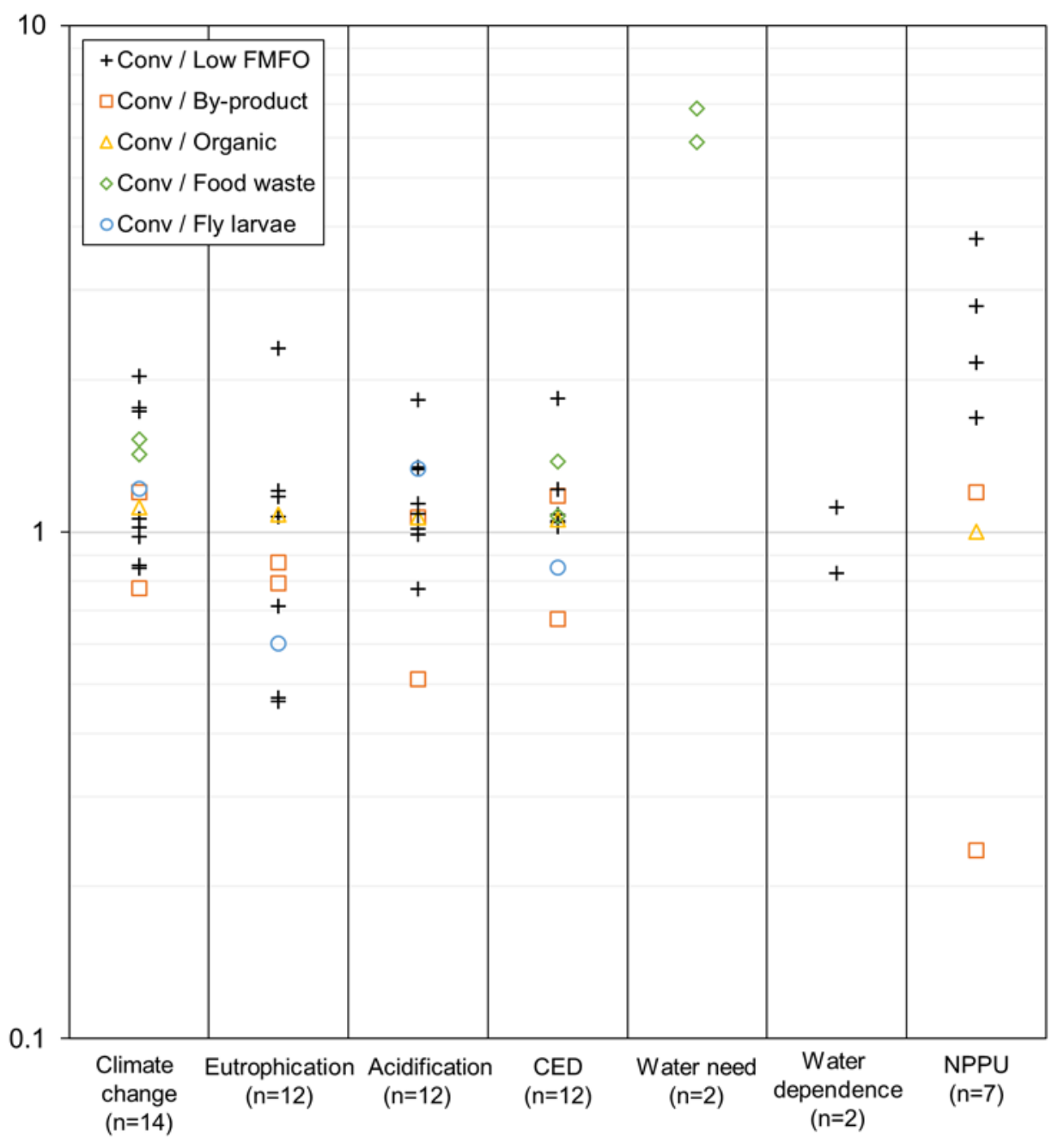

Figure 5: Ratio of the environmental impacts of conventional diet (Conv.) compared to those of different feed diets for 7 selected impacts categories. Impact scores are expressed per unit of kilogram produced. CED = cumulative energy demand; NPPU = net primary production use; FMFO: fish meal and fish oil.

\subsection{Integrated multi-trophic aquaculture: a promising approach?}

Integrated multi-trophic aquaculture (IMTA) consists in combining the production of species from different trophic or nutritional levels, such as seafood and algae. It may have the potential to decrease environmental impacts if the different species are wisely selected and combined (Bostock et al. 2010). The production of the two taxa are integrated in order to optimize the use of water, feed and fertilizers. It can for example be done by integrating a substrate on which natural food can grow or by adding filter-feeding fish (Santos et al. 2015). Two main kinds of IMTA exist: 
aquaponics and integrated agriculture-aquaculture (IAA), on which two and five LCA studies have been conducted until now, respectively (see Table 1).

Aquaponics consists of combining fish farming with hydroponics, the method of growing plants without soil. However, energy use and feed production remain the source of major environmental issues for these systems (Boxman et al. 2016; Forchino et al. 2017). To address these, optimization of management practices has been tested with focus on reducing FCR, which, combined with an increasing energy efficiency, by optimizing the water pumping, leads to important decreases in the impacts of the system (Boxman et al. 2016; Forchino et al. 2017). Additionally, infrastructures are found to be a major environmental hotspot in some aquaponics systems, and the choice of less impacting materials was reported to help decrease the environmental impacts of fish, algae and plants production (Forchino et al. 2017).

Contrarily to aquaponics, which are modern techniques and rely on highly-controlled environments, IAA has been used in China for centuries, with for instance mulberry plot-fishponds or bamboo plot-fishponds (Min and Hu 2017). In general, they show lower environmental impacts than the other alternative systems (Phong et al. 2011; Kluts et al. 2012; Henriksson et al. 2015; Jonell and Henriksson 2015). The reduced use of feed is the main source of environmental impact reduction (Kluts et al. 2012). An exception remains with aquatic eutrophication impacts, which turn out to be higher for the integrated systems if the input of natural fertilizer (usually manure) is not optimized. These cause a higher nutrient discharge to rivers during water replacement (Kluts et al. 2012), although this excess of nutrients has been reported to be recyclable to limit the high aquatic eutrophication (Henriksson et al. 2015). IAA systems therefore seem to be a promising way to manage fish farming and, owing to the very limited number of LCA studies performed on those systems, more LCA application should accompany their development. Identification of the most problematic stages or components of the systems may thus help construct more environmental-friendly systems. Additionally, collaborating with fish biologists could results in identification of optimal combinations of species.

\section{Relevance of LCA as a policy- and decision-making tool in aquaculture}

As demonstrated in the previous sections, LCA is a useful tool to identify the environmental hotspots of aquaculture systems and to compare them with each other with respect to their embedded environmental impacts. This can provide useful information to policy- and decisionmakers when it comes to encouraging development of specific types of farm installations or to introducing regulations on excessively polluting processes. It supports identification of environmental hotspots to focus development of more eco-efficient aquaculture systems and can also be useful to help consumers select products, which meet minimum environmental requirements, e.g. thanks to the use of LCA for ecolabelling (Hauschild et al. 2018). 


\subsection{Impact reduction potentials of aquaculture systems}

From the analysis of the 65 articles conducting an LCA of aquaculture systems, several potential ways to reduce environmental impacts of aquaculture can be identified. In general, wastewater and sludge management, feeding management, nutrient management and productivity are pointed out as main causes of environmental impacts from aquaculture systems. Environmental improvements on these generic aspects should therefore be undertaken by the aquaculture industry. However, as noted in Sections 4 and 5, specificities of the aquaculture systems under study (e.g. type of technologies, location, etc.) may strongly influence the impact results. This calls for performing LCA studies that are as specific to the situations and contexts as possible to allow providing relevant decision support to aquaculture stakeholders.

For example, in a situation of a new farm design, the system characteristics are important for environmental performance of the system. Polyculture or IMTA should thus be preferred to monoculture, and closed-systems with low energy requirements, along with species that have low FCR, should be prioritized (see Section 5.2). The development of aquaculture management areas, where some infrastructures and equipment (like a processing plant) are shared by a group of farmers, seems promising to reduce the impacts for small producers (Lourguioui et al. 2017). The choice of aquafeed should additionally be done carefully, aiming for formulations with less FMFO (see Section 5.2).

Existing systems can be improved by the implementation of best management practices (Avadí et al. 2015; Abdou et al. 2017a; Henriksson et al. 2017a) and the use of probiotics (live bacteria and yeasts that are assumed to be beneficial in preventing diseases) (Iribarren et al. 2012a). Both would improve disease prevention and therefore increase productivity of the farm, while reducing use of antibiotics that create antimicrobial resistance (qualified as one of the biggest threats to global health and food security today by the World Health Organization - WHO 2017). In addition, best effluent management (such as conventional practices with the addition of effluent treatment with constructed wetlands) would directly reduce the release of nutrients in the surrounding environment (Santos et al. 2015). Albeit controversial, genetically improved species have also turned out to show interesting advantages although the consequences on natural environment from potential escapes of such modified organisms have not yet been assessed (Besson et al. 2016; Henriksson et al. 2017a). Finally, utilization of co-products and by-products was found to have important potentials to decrease environmental impacts, particularly when transformed in a way that increases the output going to direct human consumption (Winther et al. 2009; Iribarren et al. 2010a; Pelletier and Tyedmers 2010).

\subsection{What can we learn from macro scale and future-oriented studies?}

Large-scale studies are especially useful for policy-making, for which evaluation of existing regulations or implementation of new ones can be assessed at national or regional scales (Gibon et al. 2015). Among the 65 reviewed studies, six LCA studies adopted a country-scale perspective 
and four others focused on a whole sector. At sector level, the LCA studies are effective at identifying high-impact practices that need to be improved (Jonell and Henriksson 2015; Nhu et al. 2016) as well as pointing out the less efficient sub-sectors (Iribarren et al. 2010c). For example, in their study on the entire mussel cultivation in Spain, Iribarren et al. (2010c) identified the dispatch centers, i.e. centers where mussels are purified, sorted and calibrated, as the most impactful sub-sector and thus as the place for policy-makers to prioritize their efforts on reducing environmental impacts.

National studies can be consumption- or production-oriented and are useful when used to inform policy-makers about the environmental sustainability of their countries. These can help them take nation-wide or sector-wide actions by assessing the sustainability of current seafood consumption in a country in the case of consumption-oriented studies (Seves et al. 2016) or giving an overview of the environmental performance of a country production facilities in the case of productionoriented studies (Winther et al. 2009). The World Fish Centre and Conservation International thus exploited the potential of this type of study in a report (Hall et al. 2011- not included in the current review because lacking peer-review), in which they conducted an LCA on over $80 \%$ of the world aquaculture production to support recommendations for stakeholders in several countries. Results of large-scale studies can thus be used in the development of more sustainable diets in specific countries or regions, based on knowledge about the impacts of the actual seafood sold in that area (Farmery et al. 2017), or in advising policy-makers regarding governmental plans for aquaculture sectorial development. For example, Henriksson et al. (2017b) performed a country-level, foresight study and compared different scenarios of seafood development in Indonesia for the next 15 years, using projections from Tran et al. (2017). They concluded that none of the tested scenarios would satisfy the government plan for development of the aquaculture sector in terms of resource needs, and recommended to prioritize more resource-efficient species and more sustainable aquaculture practices by among others farmer training, improved water management or the use of more environmental-friendly feeds. Such insights are highly useful for authorities, who may thus want to revise their planning for the future development of the entire sector. This is particularly relevant for developing countries, like Indonesia, where fast growth of the aquaculture sector is anticipated to contribute fighting nutrition challenges (FAO 2016; Tran et al. 2017). Future-oriented, country-level and/or sector-level LCA studies are thus essential to anticipate future environmental trade-offs and burden shifting and help policy-makers design adapted development plans for low-impact aquaculture systems. However, the LCA methodology, which has traditionally been applied at product level, is not always directly applicable on these largescale, foresight systems. More research to enable the conduct of such studies is therefore needed.

\subsection{Limitations of LCA to assess seafood production sustainability}

LCA is a useful tool to improve sustainability in aquaculture thanks to its full life-cycle perspective and its broad environmental impacts coverage. However, the impact categories currently covered by LCA and supported by existing LCA software remain limited in the perspective of aquaculture 
systems. A number of issues specific to aquaculture are thus not addressed, like destruction of local environment due to the mix of farmed and wild populations due to escapes (Naylor et al. 2000). In addition, some existing impact categories have a limited coverage of the causes of impacts. For example, in the assessment of toxicity-related impacts, relevant substances like antibiotics cannot yet be assessed, even though they may increase impacts on human health via antimicrobial resistance (Watts et al. 2017). Research is therefore needed to complete the set of methods for life cycle impact assessment and thus allow more comprehensive and accurate assessments of aquaculture systems. Meanwhile, we recommend combining LCA studies with other types of assessment tools to address yet-uncovered issues, such as the use of risk assessment to account for effects from antimicrobial resistance (see further details in Bohnes and Laurent 2018, submitted).

Additionally, the current availability of data concerning seafood production in LCA inventory databases is low (Farmery et al. 2017), and experts should therefore tackle that gap by gathering aquaculture data and populate such databases. Their additions to the main life-cycle inventory databases would make aquaculture assessments easier and enable a wider use of LCA in relevant regions, like Asia, where there is a current lack of LCA practice. Such efforts should also be coupled with significantly improving transparency of LCA studies conducted on aquaculture systems. As pointed out in other fields, the current lack of clarity and improper documentation of assumptions and data sources is an important barrier to the comparability of studies, thus decreasing considerably the credibility and usefulness of LCA studies in the long term and for the research community in general (Brandão et al. 2012). When such reporting standardization is effective, harmonization of the studies will be possible and thus enable the conduct of full-fledged meta-analyses.

\section{Conclusions and recommendations}

The production of seafood from aquaculture is the fastest growing food production in the world, and should be developed to be more environmentally sustainable. In our study, we reviewed 65 papers that reported LCA of aquaculture systems and aquaculture feed. At global scale, Asian and African aquaculture systems are much underrepresented in past LCA studies, even though Asian aquaculture production accounts for more than $90 \%$ of global production and seafood as an important protein source participates to food security in some African countries; more studies of Asian and African systems are therefore warranted.

Through the conducted statistical analysis, the influence of the species farmed and the FCR was found particularly determinant for environmental performances of the systems. Several ways to reduce the impacts of existing or new aquaculture systems still exist, and key recommendations are recapped below based on the findings and detailed guidance provided in Sections 3-6: 
- We recommend that seafood farmers focus on improving the general management of their production systems, with a specific attention to the management of nutrients, the water management and the choice of adapted and FCR-optimized aquafeed (see Sections 4.1 and 5.2). Some technologies have a great potential to improve environmental impacts, such as polyculture, and in particular IMTA, or low energy RAS (see Section 5).

- We recommend that policy-makers base their regulations on LCAs to improve the environmental impacts of existing and future aquaculture systems. Such regulations should be backed-up by nation-wide and/or sector-wide LCA studies to identify hotspots, (see Section 6.2). Such regulatory efforts should be complemented with initiatives that sensitize the public to sustainable seafood production, which may create market-driven call for more sustainable production schemes; the use of LCA-based ecolabelling can help in such initiatives (see Section 6.1).

- We recommend that seafood technology/system developers systematically include life cycle assessment to assist them in finding as environmentally-sustainable systems/technologies as possible when working on improving productivity. As part of our review, environmental hotspots were identified for a number of specific technologies and systems; these may also serve as basis to improve existing systems and develop new ones (see, e.g. Sections 4.1 and 5.1).

- We recommend that consistent and detailed guidelines on how to apply the LCA methodology to aquaculture systems be developed to improve the consistency and comparability of studies (see Bohnes and Laurent 2018, submitted). To reach that aim, the transparency in reporting the scope and inventory phases of LCA studies should be a priority for LCA practitioners. LCA method developers should additionally extend the range of existing impact categories to include new impact categories specific to the aquaculture sector, for example enabling assessing the reduction of antimicrobial resistance to unveil potential environmental trade-offs with commonly-assessed categories of impacts (see Bohnes and Laurent 2018, submitted).

\section{Acknowledgements}

We thank Dr. Hu Chengcheng and Dr. Shi Jiahua (NTU NAFTEC) for their suggestions and comments that contributed to improve the article, and we also thank Associate Professor Anders Stockmarr (DTU Compute) for his useful advices regarding the statistical analysis. 


\section{References:}

Abdou, K., Ben Rais Lasram, F., Romdhane, M.S., Le Loc’h, F. and Aubin, J. (2017a) Rearing performances and environmental assessment of sea cage farming in Tunisia using life cycle assessment (LCA) combined with PCA and HCPC. The International Journal of Life Cycle Assessment, 1-14.

Abdou, K., Aubin, J., Romdhane, M.S., Le Loc’h, F. and Lasram, F.B.R. (2017b) Environmental assessment of seabass (Dicentrarchus labrax) and seabream (Sparus aurata) farming from a life cycle perspective: A case study of a Tunisian aquaculture farm. Aquaculture 471, 2042012.

Andersson, K. (2000) LCA of food products and production systems. The International Journal of Life Cycle Assessment 5, 239-248.

Aubin, J. (2013) Life Cycle Assessment as applied to environmental choices regarding farmed or wild-caught fish. CAB Reviews: Perspectives in Agriculture, Veterinary Science, Nutrition and Natural Resources 8, 1-10.

Aubin, J., Baruthio, A., Mungkung, R. and Lazard, J. (2015) Environmental performance of brackish water polyculture system from a life cycle perspective: A Filipino case study. Aquaculture 435, 217-227.

Aubin, J. and Fontaine, C. (2014) Impacts of producing bouchot mussels in Mont-Saint-Michel Bay (France) using LCA with emphasis on potential climate change and eutrophication. In: Proceedings of the 9th International Conference on Life Cycle Assessment in the Agri-Food Sector Environmental. pp 64-69.

Aubin, J., Papatryphon, E., van der Werf, H.M.G. and Chatzifotis, S. (2009) Assessment of the environmental impact of carnivorous finfish production systems using life cycle assessment. Journal of Cleaner Production 17, 354-361.

Aubin, J., Papatryphon, E., Van der Werf, H.M.G., Petit, J. and Morvan, Y.M. (2006) Characterisation of the environmental impact of a turbot (Scophthalmus maximus) recirculating production system using Life Cycle Assessment. Aquaculture 261, 1259-1268.

Auburn University (2017) Introduction to polyculture. Available at: http://www.ag.auburn.edu/fish/documents/International_Pubs/Water Harvesting/English/Introduction to polyculture.pdf [Accessed November 6, 2017].

Avadí, A., Pelletier, N., Aubin, J., Ralite, S., Núñez, J. and Fréon, P. (2015) Comparative environmental performance of artisanal and commercial feed use in Peruvian freshwater aquaculture. Aquaculture 435, 52-66.

Ayer, N., Martin, S., Dwyer, R.L., Gace, L. and Laurin, L. (2016) Environmental performance of copper-alloy Net-pens: Life cycle assessment of Atlantic salmon grow-out in copper-alloy and nylon net-pens. Aquaculture 453, 93-103.

Ayer, N.W. and Tyedmers, P.H. (2009) Assessing alternative aquaculture technologies: life cycle assessment of salmonid culture systems in Canada. Journal of Cleaner Production 17, 362- 
Bohnes F.A., Hauschild M.Z., Schlundt J. and Laurent A., 2018. Life cycle assessments of aquaculture systems: a critical review of reported findings with recommendations for policy and system development. Reviews in aquaculture, 1-19. DOI: 10.1111/raq.12280

373.

Baruthio, A., Aubin, J., Mungkung, R., Lazard, J. and Van der Werf, H.M. (2008) Environmental assessment of Filipino fish/prawn polyculture using Life Cycle Assessment. In: Proceedings of the 6th International Conference on LCA in the Agri-Food Sector. Zurich, Switzerland, pp 242-247.

Besson, M., Aubin, J., Komen, H., et al. (2016) Environmental impacts of genetic improvement of growth rate and feed conversion ratio in fish farming under rearing density and nitrogen output limitations. Journal of Cleaner Production 116, 100-109.

Bohnes, F.A., and Laurent, A. (2018) LCA of aquaculture systems: methodological issues and potential improvements. Submitted (06/2018).

Boissy, J., Aubin, J., Drissi, A., van der Werf, H.M.G., Bell, G.J. and Kaushik, S.J. (2011) Environmental impacts of plant-based salmonid diets at feed and farm scales. Aquaculture 321, 61-70.

Bostock, J., McAndrew, B., Richards, R., et al. (2010) Aquaculture: global status and trends. Philosophical Transactions of the Royal Society B: Biological Sciences 365, 2897-2912.

Boxman, S.E., Zhang, Q., Bailey, D. and Trotz, M.A. (2016) Life Cycle Assessment a Commercial-Scale Freshwater Aquaponic System. Environmental Engineering Science 34, 299-311.

Brandão, M., Heath, G. and Cooper, J. (2012) What Can Meta-Analyses Tell Us About the Reliability of Life Cycle Assessment for Decision Support? Journal of Industrial Ecology 16, 3-7.

Cao, L., Diana, J.S. and Keoleian, G.A. (2013) Role of life cycle assessment in sustainable aquaculture. Reviews in Aquaculture 5, 61-71.

Cao, L., Diana, J.S., Keoleian, G.A. and Lai, Q. (2011) Life cycle assessment of Chinese shrimp farming systems targeted for export and domestic sales. Environmental Science and Technology 45, 6531-6538.

Cashion, T., Hornborg, S., Ziegler, F., Hognes, E.S. and Tyedmers, P. (2016) Review and advancement of the marine biotic resource use metric in seafood LCAs: a case study of Norwegian salmon feed. International Journal of Life Cycle Assessment 21, 1106-1120.

Clark, M. and Tilman, D. (2017) Comparative analysis of environmental impacts of agricultural production systems, agricultural input efficiency, and food choice. Environmental Research Letters 12, 1-11.

Dekamin, M., Veisi, H., Safari, E., Liaghati, H., Khoshbakht, K. and Dekamin, M.G. (2015) Life cycle assessment for rainbow trout (Oncorhynchus mykiss) production systems: A case study for Iran. Journal of Cleaner Production 91, 43-55.

Diana, J.S. (2009) Aquaculture Production and Biodiversity Conservation. BioScience 59, 27-38. EC (2010) International Reference Life Cycle Data System (ILCD) Handbook: General guide for 
Bohnes F.A., Hauschild M.Z., Schlundt J. and Laurent A., 2018. Life cycle assessments of aquaculture systems: a critical review of reported findings with recommendations for policy and system development. Reviews in aquaculture, 1-19. DOI: 10.1111/raq.12280

Life Cycle Assessment - Detailed guidance, First Edit. Publications Office of the European Union, Luxembourg.

Efole Ewoukem, T., Aubin, J., Mikolasek, O., et al. (2012) Environmental impacts of farms integrating aquaculture and agriculture in Cameroon. Journal of Cleaner Production 28, 208-214.

Ellingsen, H. and Aanondsen, S.A. (2006) Environmental Impacts of Wild Caught Cod and Farmed Salmon - A Comparison with Chicken. The International Journal of Life Cycle Assessment 11, 60-65.

EUMOFA (2015) The EU Fish Market. Brussels, BE: European Commission.

FAO (2017a) CWP Handbook of Fishery Statistical Standards. Section J: AQUACULTURE. Available at: http://www.fao.org/fishery/cwp/handbook/j/en [Accessed May 17, 2017].

FAO (2018) Feed formulae (ingredient composition) and proximate composition of commonly used formulated feed for different life stages of Atlantic salmon in intensive farming system. Available at:

http://www.fao.org/fileadmin/user_upload/affris/docs/Atlantic_Salmon/table_3.htm.

FAO. (2017b). Fishery and Aquaculture Statistics. [Global capture production 1950-2015] (FishStatJ) In: FAO Fisheries and Aquaculture Department [online or CD-ROM]. Rome, IT. http://www.fao.org/fishery/statistics/software/FishStatJ/en.

FAO (2016) The State of World Fisheries and Aquaculture. Food and Agriculture Organisation of the United Nations, Rome, IT.

Farmery, A.K., Gardner, C., Jennings, S., Green, B.S. and Watson, R.A. (2017) Assessing the inclusion of seafood in the sustainable diet literature. Fish and Fisheries 18, 607-618.

Forchino, A.A., Lourguioui, H., Brigolin, D. and Pastres, R. (2017) Aquaponics and sustainability: the comparison of two different aquaponic 2 techniques using the Life Cycle Assessment (LCA). Aquacultural Engineering 77, 80-88.

Fréon, P., Durand, H., Avadí, A., Huaranca, S. and Orozco Moreyra, R. (2017) Life cycle assessment of three Peruvian fishmeal plants: Toward a cleaner production. Journal of Cleaner Production 145, 50-63.García García, B., Rosique Jiménez, C., Aguado-Giménez, F. and García García, J. (2016) Life Cycle Assessment of Gilthead Seabream (Sparus aurata) Production in Offshore Fish Farms. Sustainability 8, 1228.

Gibon, T., Wood, R., Arvesen, A., Bergesen, J.D., Suh, S. and Hertwich, E.G. (2015) A Methodology for Integrated, Multiregional Life Cycle Assessment Scenarios under LargeScale Technological Change. Environmental Science and Technology 49, 11218-11226.

Goedkoop, M., Heijungs, R., De Schryver, A., Struijs, J. and van Zelm, R. (2013) ReCiPe 2008. A LCIA method which comprises harmonised category indicators at the midpoint and the endpoint level. Report I: Characterisation. The Netherlands: Dutch Ministry of Housing, Spatial Planning and Environment. 
Bohnes F.A., Hauschild M.Z., Schlundt J. and Laurent A., 2018. Life cycle assessments of aquaculture systems: a critical review of reported findings with recommendations for policy and system development. Reviews in aquaculture, 1-19. DOI: 10.1111/raq.12280

Goodland, R. (1995) The Concept of Environmental Sustainability. Annual Review of Ecology and Systematics 26, 1-24.

Goodland, R. and Daly, H. (1996) ENVIRONMENTAL SUSTAINABILITY: UNIVERSAL AND NON-NEGOTIABLE. 6, 1002-1017.

Grönroos, J., Seppälä, J., Silvenius, F. and Mäkinen, T. (2006) Life cycle assessment of Finnish cultivated rainbow trout. Boreal Environment Research 11, 401-414.

Hall, S., Delaporte, A., Phillips, M.J., Beveridge, M. and O’Keefe, M. (2011) BLUE FRONTIERS Managing the environmental costs of aquaculture. Penang, Malaysia.

Hauschild, M., Rosenbaum, R.K. and Olsen, S.I. (2018) Life Cycle Assessment - Theory and Practice. Switzerland: Springer International Publishing.

Heath, G.A. and Mann, M.K. (2012) Background and Reflections on the Life Cycle Assessment Harmonization Project. Journal of Industrial Ecology 16, 8-11.

Hellweg, S. and Milà i Canals, L. (2014) Emerging approaches, challenges and opportunities in life cycle assessment. Science 344, 1109-1113.

Henriksson, P.J.G., Dickson, M., Allah, A.N., Al-Kenawy, D. and Phillips, M. (2017a) Benchmarking the environmental performance of best management practice and genetic improvements in Egyptian aquaculture using life cycle assessment. Aquaculture 468, 5359.

Henriksson, P.J.G., Guinée, J.B., Kleijn, R. and De Snoo, G.R. (2012) Life cycle assessment of aquaculture systems-A review of methodologies. International Journal of Life Cycle Assessment 17, 304-313.

Henriksson, P.J.G., Rico, A., Zhang, W., et al. (2015) Comparison of Asian Aquaculture Products by Use of Statistically Supported Life Cycle Assessment. Environmental Science and Technology 49, 14176-14183.

Henriksson, P.J.G., Tran, N., Mohan, C.V., et al. (2017b) Indonesian aquaculture futures Evaluating environmental and socioeconomic potentials and limitations. Journal of Cleaner Production 162, 1482-1490.

Iribarren, D., Dagá, P., Moreira, M.T. and Feijoo, G. (2012a) Potential environmental effects of probiotics used in aquaculture. Aquaculture International 20, 779-789.

Iribarren, D., Moreira, M.T. and Feijoo, G. (2010a) Implementing by-product management into the life cycle assessment of the mussel sector. Resources, Conservation and Recycling 54, 1219-1230.

Iribarren, D., Moreira, M.T. and Feijoo, G. (2010b) Life Cycle Assessment of fresh and canned mussel processing and consumption in Galicia (NW Spain). Resources, Conservation and Recycling 55, 106-117.

Iribarren, D., Moreira, M.T. and Feijoo, G. (2012b) Life cycle assessment of aquaculture feed and application to the turbot sector. International Journal of Environmental Research $\mathbf{6}$, 
Bohnes F.A., Hauschild M.Z., Schlundt J. and Laurent A., 2018. Life cycle assessments of aquaculture systems: a critical review of reported findings with recommendations for policy and system development. Reviews in aquaculture, 1-19. DOI: 10.1111/raq.12280

837-848.

Iribarren, D., Moreira, M.T. and Feijoo, G. (2010c) Revisiting the Life Cycle Assessment of mussels from a sectorial perspective. Journal of Cleaner Production 18, 101-111.

ISO (2006) ISO 14044:2006 - Environmental management - Life cycle assessment Requirements and guidelines. Geneva, Switzerland.

Jerbi, M.A., Aubin, J., Garnaoui, K., Achour, L. and Kacem, A. (2012) Life cycle assessment (LCA) of two rearing techniques of sea bass (Dicentrarchus labrax). Aquacultural Engineering 46, 1-9.

Jonell, M. and Henriksson, P.J.G. (2015) Mangrove-shrimp farms in Vietnam-Comparing organic and conventional systems using life cycle assessment. Aquaculture 447, 66-75.

Klinger, D. and Naylor, R. (2012) Searching for Solutions in Aquaculture: Charting a Sustainable Course. Annual Review of Environment and Resources 37, 247-276.

Kluts, I.N., Potting, J., Bosma, R.H., Phong, L.T. and Udo, H.M.J. (2012) Environmental comparison of intensive and integrated agriculture-aquaculture systems for striped catfish production in the Mekong Delta, Vietnam, based on two existing case studies using life cycle assessment. Reviews in Aquaculture 4, 195-208.

Laurent, A., Espinosa, N. and Hauschild, M.Z. (2018) LCA of Energy Systems. In: Life Cycle Assessment: Theory and Practice. (ed Hauschild M.Z. et al.). Springer, Dordrecht, NL, pp 633-668.

Laurent, A., Olsen, S.I. and Hauschild, M.Z. (2011) Normalization in EDIP97 and EDIP2003: Updated European inventory for 2004 and guidance towards a consistent use in practice. International Journal of Life Cycle Assessment 16, 401-409.

Lifset, R. (2012) Toward Meta-Analysis in Life Cycle Assessment. Journal of Industrial Ecology 16, 1-2.

Lourguioui, H., Brigolin, D., Boulahdid, M. and Pastres, R. (2017) A perspective for reducing environmental impacts of mussel culture in Algeria. International Journal of Life Cycle Assessment, 1-12.

Martins, C.I.M., Eding, E.H., Verdegem, M.C.J., et al. (2010) New developments in recirculating aquaculture systems in Europe: A perspective on environmental sustainability. Aquacultural Engineering 43, 83-93.

McGrath, K.P., Pelletier, N.L. and Tyedmers, P.H. (2015) Life cycle assessment of a novel closed-containment salmon aquaculture technology. Environmental Science and Technology 49, 5628-5636.

Medeiros, M. V., Aubin, J. and Camargo, A.F.M. (2017) Life cycle assessment of fish and prawn production: Comparison of monoculture and polyculture freshwater systems in Brazil. Journal of Cleaner Production 156, 528-537.

Min, K. and Hu, B. (2017) Chinese embankment fish culture. Available at: 
Bohnes F.A., Hauschild M.Z., Schlundt J. and Laurent A., 2018. Life cycle assessments of aquaculture systems: a critical review of reported findings with recommendations for policy and system development. Reviews in aquaculture, 1-19. DOI: 10.1111/raq.12280

http://www.fao.org/docrep/005/Y1187E/y1187e09.htm [Accessed November 6, 2017].

Mungkung, R. and Gheewala, S. 2007. Use of life cycle assessment (LCA) to compare the environmental impacts of aquaculture and agri-food products. In D.M. Bartley, C. Brugère, D. Soto, P. Gerber and B. Harvey (eds). Comparative assessment of the environmental costs of aquaculture and other food production sectors: methods for meaningful comparisons. FAO/WFT Expert Workshop. 24-28 April 2006, Vancouver, Canada. FAO Fisheries Proceedings. No. 10. Rome, FAO. 2007. pp. 87-96.

Mungkung, R., Udo de Haes, H. and Clift, R. (2006) Potentials and Limitations of Life Cycle Assessment in Setting Ecolabelling Criteria: A Case Study of Thai Shrimp Aquaculture Product (5 pp). The International Journal of Life Cycle Assessment 11, 55-59.

Mungkung, R., Aubin, J., Prihadi, T.H., Slembrouck, J., Van Der Werf, H.M.G. and Legendre, M. (2013) Life cycle assessment for environmentally sustainable aquaculture management: A case study of combined aquaculture systems for carp and tilapia. Journal of Cleaner Production 57, 249-256.

Naylor, R.L., Goldburg, R.J., Primavera, J.H., et al. (2000) Effect of aquaculture on world fish supplies. Nature 405, 1017-24.

Nhu, T.T., Schaubroeck, T., Henriksson, P.J.G., Bosma, R., Sorgeloos, P. and Dewulf, J. (2016) Environmental impact of non-certified versus certified (ASC) intensive Pangasius aquaculture in Vietnam, a comparison based on a statistically supported LCA. Environmental Pollution 219, 156-165.

Nijdam, D., Rood, T. and Westhoek, H. (2012) The price of protein: Review of land use and carbon footprints from life cycle assessments of animal food products and their substitutes. Food Policy 37, 760-770.

Ottinger, M., Clauss, K. and Kuenzer, C. (2016) Aquaculture: Relevance, distribution, impacts and spatial assessments - A review. Ocean and Coastal Management 119, 244-266.

Pahri, S.D.R., Mohamed, A.F. and Samat, A. (2015) LCA for open systems: a review of the influence of natural and anthropogenic factors on aquaculture systems. The International Journal of Life Cycle Assessment, 1324-1337.

Pahri, S.D.R., Mohamed, A.F. and Samat, A. (2016) Life cycle assessment of Cockles (Anadara granosa) farming: a case study of Malaysia. Environment Asia 9, 80-90.

Papatryphon, E., Petit, J., Kaushik, S.J. and Van Der Werf, H.M.G. (2004) Environmental impact assessment of salmonid feeds using Life Cycle Assessment (LCA). Ambio 33, 316-323.

Parker, R. (2012) Review of life cycle assessment research on products derived from fisheries and aquaculture : A report for Seafish as part of the collective action to address greenhouse gas emissions in seafood. Edinburgh, UK: Sea Fish Industry Authority.

Pelletier, N. and Tyedmers, P. (2007) Feeding farmed salmon: Is organic better? Aquaculture 272, 399-416. 
Bohnes F.A., Hauschild M.Z., Schlundt J. and Laurent A., 2018. Life cycle assessments of aquaculture systems: a critical review of reported findings with recommendations for policy and system development. Reviews in aquaculture, 1-19. DOI: 10.1111/raq.12280

Pelletier, N. and Tyedmers, P. (2010) Life cycle assessment of frozen tilapia fillets from indonesian lake-based and pond-based intensive aquaculture systems. Journal of Industrial Ecology 14, 467-481.

Pelletier, N., Tyedmers, P., Sonesson, U., et al. (2009) Not all salmon are created equal: Life cycle assessment (LCA) of global salmon farming systems. Environmental Science and Technology 43, 8730-8736.

Phong, L.T., de Boer, I.J.M. and Udo, H.M.J. (2011) Life cycle assessment of food production in integrated agriculture-aquaculture systems of the Mekong Delta. Livestock Science 139, 8090.

Roque d’Orbcastel, E., Blancheton, J.-P. and Aubin, J. (2009) Towards environmentally sustainable aquaculture: Comparison between two trout farming systems using Life Cycle Assessment. Aquacultural engineering 40, 113-119.

R Core Team (2013). R: A language and environment for statistical computing. R Foundation for Statistical Computing, Vienna, Austria. ISBN 3-900051-07-0, URL http://www.Rproject.org/.

Samuel-Fitwi, B., Meyer, S., Reckmann, K., Schroeder, J.P. and Schulz, C. (2013a) Aspiring for environmentally conscious aquafeed: Comparative LCA of aquafeed manufacturing using different protein sources. Journal of Cleaner Production 52, 225-233.

Samuel-Fitwi, B., Nagel, F., Meyer, S., Schroeder, J.P. and Schulz, C. (2013b) Comparative life cycle assessment (LCA) of raising rainbow trout (Oncorhynchus mykiss) in different production systems. Aquacultural Engineering 54, 85-92.

Samuel-Fitwi, B., Schroeder, J.P. and Schulz, C. (2013c) System delimitation in life cycle assessment (LCA) of aquaculture: Striving for valid and comprehensive environmental assessment using rainbow trout farming as a case study. International Journal of Life Cycle Assessment 18, 577-589.

Santos, A.A.O., Aubin, J., Corson, M.S., Valenti, W.C. and Camargo, A.F.M. (2015) Comparing environmental impacts of native and introduced freshwater prawn farming in Brazil and the influence of better effluent management using LCA. Aquaculture 444, 151-159.

Seghetta, M., Romeo, D., D’Este, M., Alvarado-Morales, M., Angelidaki, I., Bastianoni, S. and Thomsen, M. (2017) Seaweed as innovative feedstock for energy and feed - Evaluating the impacts through a Life Cycle Assessment. Journal of Cleaner Production 150, 1-15.

Seves, S.M., Temme, E.H.M., Brosens, M.C.C., Zijp, M.C., Hoekstra, J. and Hollander, A. (2016) Sustainability aspects and nutritional composition of fish: evaluation of wild and cultivated fish species consumed in the Netherlands. Climatic Change 135, 597-610.

Sleeswijk, A.W., van Oers, L.F.C.M., Guinée, J.B., Struijs, J. and Huijbregts, M.A.J. (2008) Normalisation in product life cycle assessment: An LCA of the global and European economic systems in the year 2000. Science of the Total Environment 390, 227-240.

Smárason, B.Ö., Ögmundarson, Ó., Árnason, J., Björnsdóttir, R. and Davíðsdóttir, B. (2017) Life 
Cycle Assessment of Icelandic Arctic Char Fed Three Different Feed Types. Turkish Journal of Fisheries and Aquatic Sciences 17, 79-90.

Soliman, N.F. and Yacout, D.M.M. (2015) The Prospects of Analysing the Environmental Impacts of Egyptian Aquaculture Using Life Cycle Assessment. International Journal of Aquaculture 5, 1-9.

Strazza, C., Magrassi, F., Gallo, M. and Del Borghi, A. (2015) Life Cycle Assessment from food to food: A case study of circular economy from cruise ships to aquaculture. Sustainable Production and Consumption 2, 40-51.

Tlusty, M.F. and Thorsen, Ø. (2016) Claiming seafood is "sustainable” risks limiting improvements. Fish and Fisheries 18, 340-346.

Tran, N., Rodriguez, U.P., Chan, C.Y., et al. (2017) Indonesian aquaculture futures: An analysis of fish supply and demand in Indonesia to 2030 and role of aquaculture using the AsiaFish model. Marine Policy 79, 25-32.

Watts, J., Schreier, H., Lanska, L. and Hale, M. (2017) The Rising Tide of Antimicrobial Resistance in Aquaculture: Sources, Sinks and Solutions. Marine Drugs 15, 158.

WHO (2017) Antibiotic resistance. Available at: http://www.who.int/mediacentre/factsheets/antibiotic-resistance/en/ [Accessed November 6, 2017].

Wilfart, A., Prudhomme, J., Blancheton, J.P. and Aubin, J. (2013) LCA and emergy accounting of aquaculture systems: Towards ecological intensification. Journal of Environmental Management 121, 96-109.

Winther, U., Ziegler, F., Hognes, E.S., Emanuelsson, A., Sund, V. and Ellingsen, H. (2009) Carbon footprint and energy use of Norwegian seafood products. Trondheim, NO: SINTEF Fisheries and Aquaculture.

World Bank (2013) Fish to 2030: Prospects for fisheries and aquaculture. Washington, DC: The World Bank.

Yacout, D.M.M.., Soliman, N.F.. and Yacout, M.M.. (2016) Comparative life cycle assessment (LCA) of Tilapia in two production systems: semi-intensive and intensive. International Journal of Life Cycle Assessment 21, 806-819.

Ziegler, F., Hornborg, S., Green, B.S., et al. (2016) Expanding the concept of sustainable seafood using Life Cycle Assessment. Fish and Fisheries 17, 1073-1093. 